\title{
Bi-regional Scientific Cooperation on Food and Nutrition Security and Sustainable Agriculture
}

\author{
Jean Albergel, Arlène Alpha, Noubou Diaby, \\ Judith-Ann Francis, Jacques Lançon, Jean-Michel Sers, \\ and Johan Viljoen
}

\begin{abstract}
This chapter argues that Africa-Europe cooperation still faces two significant challenges: first, the practical implementation of innovative solutions to the challenge of assuring food security is still lagging behind;
\end{abstract}

J. Albergel $(\bowtie) \bullet J$. Viljoen

IRD-CNRS-CIRAD Joint Office In Pretoria, Institut de Recherche pour le Développement (IRD), The Innovation Hub, Pretoria, South Africa
A. Alpha • J. Lançon • J.-M. Sers
Centre de Coopération Internationale en Recherche Agronomique pour le Développement (CIRAD), Paris, France
N. Diaby

Université Cheikh Anta Diop, Dakar, Senegal

J.-A. Francis

Technical Centre for Agricultural and Rural Cooperation ACP-EU, Wageningen, The Netherlands

(C) The Author(s) 2018 
second, equal partnerships still need to be further institutionalised in order to become more enabling of positive change. As food and nutrition security issues touch on structural socio-economic, political and even environmental constraints, they require extensive networks of research, innovation and institutional collaboration. Despite several achievements, persisting asymmetries continue to burden the achievement of food and nutrition security goals in Sub-Saharan Africa. The authors point out the strategic role that African countries could play first in cooperating with less developed European countries and in promoting alternative concepts of nutrition and environmental development on the global stage.

Keywords Innovative solution $\bullet$ Equal benefits $\bullet$ Global development • Harmonised resources $\bullet$ Geographical representation $\bullet$ Agricultural platforms $\bullet$ Poverty $\bullet$ Health $\bullet$ Productivity

\section{INTRODUCTION}

Globalisation has changed the way knowledge is produced, shared and used. Major global challenges such as climate change, poverty, infectious disease, threats to energy, food and water supply, security and the digital divide highlight the need for effective global science, technology and innovation (STI) cooperation to promote sustainable development, notably in the developing world (European Commission 2009). In Africa, governments have recognised the importance of STI for this purpose, and as a result, the African Ministerial Conference on Science and Technology adopted the Consolidated Plan of Action (CPA) on STI in 2005 (see also Chap. 2). The CPA has since been revised as the Science, Technology and Innovation Strategy for Africa (STISA-2024), endorsed by African Heads of State and Government in July 2014 (NEPAD 2014).

Eradicating hunger and achieving food and nutrition security and sustainable agriculture (FNSSA) is one of the six priority areas of STISA-2024, while strengthening international cooperation is identified as one of the mechanisms for implementing actions in pursuit of using STI for socio-economic development and growth on the continent. In this way, the strategy is not only well aligned to its European counterpart (the Common Agricultural Policy) as well as placed squarely within the Joint Africa-EU Strategy (JAES) for region-to-region scientific cooperation and partnership. It is also fully a part of an increasing drive towards ownership 
of the agricultural science agenda by African countries themselves. This drive is championed by, among others, the Forum for Agricultural Research in Africa (FARA) and articulated in the document Science Agenda for Agriculture in Africa —also known as S3A (FARA 2013) — which was similarly endorsed by African leaders in 2014. Set against this policy backdrop, this chapter critically discusses the relationship between Africa and Europe in the domain of FNSSA. It highlights the extent to which FNSSA has featured within bi-regional STI cooperation more broadly, and it identifies critical success factors for FNSSA project partnerships.

\section{Situational AnAlysis}

The idea that agriculture in Africa is too important to be outsourced has led to the creation of several platforms operating at continental and sub-regional level and, similar to FARA, aiming at encouraging African countries to invest in sufficient scientific capacity to support agricultural transformation. Examples of platforms operating at continental and sub-regional level include the Association for Strengthening Agricultural Research in Eastern and Central Africa (ASARECA), the Conseil Ouest et Centre Africain pour la Recherche et le Développement Agricoles/West and Central African Council for Agricultural Research and Development (CORAF/WECARD) and the Centre for Coordination of Agricultural research and Development for Southern Africa (CCARDESA). These platforms coordinate the implementation of such programmes by facilitating collaboration among stakeholders and carrying out capacity building initiatives. Additional key functions of these platforms include knowledge management and dissemination, as well providing direct inputs into policymaking organs at national, regional, continental and international levels, including the African Union Commission (AUC), the New Partnership for Africa's Development Agency (NEPAD), the European Union (EU) and the World Bank.

As the preceding discussion points out, many well-documented and clearly articulated agricultural programmes and policies have been developed to address FNSSA in Sub-Saharan Africa. In addition, many African governments, regional bodies and organisations have been deeply involved in implementing strategic food policies and exploring research priorities. As previous chapters have noted, the need for cooperation at national, regional and international level is widely acknowledged, both politically and within the associated policy frameworks. Similarly, the need to increase food supply by raising production capacities, harnessing trade and improving natural resources management has repeatedly been emphasised. The pan-African policy framework established by the United 
Nations, the Comprehensive Africa Agriculture Development Programme (CAADP) and NEPAD's Framework for African Food Security (FAFS) also recognised the need for a better application and optimisation of new technologies, and for improving the diversity and quality of diets.

Priorities for FNSSA in Sub-Saharan Africa are much broader than just increasing availability: poverty, food insecurity, poor health and malnutrition are interrelated issues also affected by the lack of political stability, environmental degradation and limited technical capacities. All these areas impact food productivity and are intended to be addressed by other cooperation programmes. Yet, despite the elaboration of most of these policies and programmes, poverty, hunger and malnutrition are still high in African countries: the UN Food and Agriculture Organization (FAO) estimates that, in 2014-2016, 233 million people in Sub-Saharan Africa were hungry/undernourished. The FNSSA goal remains to be achieved. As with other such intractable issues or wicked problems, such failure suggests a missing link between research outputs and FNSSA realities.

Outcome Testimonial: Increasing access by Beninese small- and mediumsized enterprises' (SMEs) to global markets by improving the quality of food products. Compiled by Andrea Cefis (Belgian Development Agency, Benin).

As a result of the "shrimp crisis", a food safety scare in 2002, Benin banned the export of the shellfish to Europe to avoid international sanctions as a response to inadequate food safety control systems operating in the country. This situation had a significant negative economic impact on Beninese industry and exports. In 2012, the European Commission (EC) and the Government of the Republic of Benin, in collaboration with the Belgian Development Agency, provided a 2.8 million euros grant to initiate the "Improving Food Safety" project. Running until May 2017, the objective of this Africa-Europe collaboration was to develop an adequate food safety control system, thereby helping SMEs to improve the quality of their food products and, at the same time, to strengthen the competitiveness of the country's products in international markets.

The project operated on three levels. First, the Beninese Food Safety Agency used it to refine a food security policy based on food safety risk analyses, and to design an improved food control system for assessing the adequacy of food safety. Second, the Laboratory for Control of Sanitary Food Safety (LCSSA) used the project to strengthen the analytical capacity of it research staff. As a result, in March 2016 the LCSSA was accredited according to the international ISO 17025 standard, allowing Benin to boast an approved international laboratory and enabling private industries to perform globally accepted product analyses locally before exportation. Third, on the private sector level, the project 
supported agri-food industries by training staff of SMEs to implement food bygiene initiatives, including Hazard Analysis Critical Control Point (HACCP).

Positive outcomes of the project are already visible: 18 Beninese SMEs have implemented HACCP, allowing them to export their products to Europe and the United States - for instance, cashew producers have obtained contracts with American enterprises and pineapple juice producers with French customers. Local producers of spirulina (blue-green algae used in numerous food products) now sell their goods to international institutions such as FAO and WHO (World Health Organization) to combat malnutrition. Furthermore, the Improving Food Safety project helped other agri-food industries, such as pineapple production, to develop food hygiene policies, while similar initiatives are now supporting agri-food industries to achieve conformity to international food hygiene standards such as ISO 22000, GLOBALGAP and ECOCERT.

\section{The Realisation of FNSSA Priorities in Africa- Europe STI COOPERATION}

Europe-Africa STI collaboration has a long history that can in part be traced to 1983, when the EU's international cooperation on research programming commenced. Its benefits have been confirmed in more recent years by the increasing number of joint projects (including on FNSSA), their budgetary allocations, and the number of participating organisations involved (see also Chap. 3). More specifically, the EU has been instrumental in supporting continental and sub-regional research coordination platforms dealing with FNSSA, such as FARA and ASARECA, as well as Africa-EU bi-regional platforms such as PAEPARD (The Platform for African European Partnership on Agricultural Research for Development). In 2007, the JAES was adopted in response to new geopolitical changes, globalisation and the processes of integration on the two continents: it was the expression of an overtly political partnership that distinguished itself from the previous Africa-Europe policy initiatives by pointing out the need to address joint priorities for a more egalitarian and mutually beneficial cooperation.

In this context, the positive contributions of scientific and technological research, development and innovation together with the acknowledged role of research capacity for economic and social growth, as well as poverty alleviation have become explicit-in particular for building knowledge-based societies and addressing global societal challenges of mutual interest. The High Level Policy Dialogue (HLPD), 
which sets the agenda for the EU-Africa STI partnership and oversees progress, is also a forum for sharing and disseminating ideas to inform development policies at national and regional level.

Although FNSSA remains high on the list of priorities for AfricaEurope collaboration, the extent to which this collaboration has been successful in responding to the issue is in question. Partial progress is certainly undeniable: FNSSA is no longer limited to agricultural issues, as nutrition has become increasingly important. Indeed, several projects under Horizon 2020 such as LEAP-AGRI (see below) have been launched as part of the Africa-EU FNSSA partnership under the JAES. Whereas the "key" issues were previously restricted to producing bigger crops through more intensive growing practices, FNSSA is now considered much more broadly and includes, in relation to the sustainability of production and transformation systems, their impact on livelihood and ecosystem services. Other concerns, such as how to add value and create jobs, the efficiency of production models (large versus small-scale farming), access to market and entrepreneurship, and the food system as a whole have also become mainstreamed.

The JAES action plan insufficiently addressed the FNSSA priorities outlined in CAADP and in pillars III and IV specifically. However, the issue has more recently secured greater attention and support, and manifested in a bi-regional research and innovation (R\&I) partnership on FNSSA established in 2016. Significant challenges remain though in ensuring that all the available knowledge is used to inform policy, improve food systems and processes, expand product range, markets and trade and support innovation for social and economic gain in both Europe and Africa. Indeed, only a few projects of the CAADP-FAFS actually address food stability as a priority issue; and private sector involvement in EU research framework programmes is poorly represented (about $\mathbf{1 5 . 5 \%}$ of the participants) and so is civil society (only $1.5 \%$ of participating organisations). A major barrier to private sector engagement has been the differing motivations of business enterprises and research institutions, and the limited follow-through on research outputs after projects ended. The transfer and dissemination of knowledge also remains limited, as farmers often do not see the direct benefits of research cooperation projects. All of this suggests a dearth of mechanisms for making the knowledge available, understandable and convincing.

Future engagement in this area should focus on mechanisms to improve the accessibility of the outputs of joint Africa-Europe research cooperation as well as on making the knowledge accessible to a wider public. In addition, the enhanced capacity and knowledge created through cooperation 
should be used to improve STI, agriculture and FNSSA policy processes on both continents as well as to bring about greater synergy among the various policy instruments and implementing agencies. While this may be occurring to some extent already, ensuring greater continental, regional and national ownership of the FNSSA research and policy agendas, and developing a more robust research infrastructure (particularly in Africa) is sorely needed.

\section{Critical Factors for Better and More Frequent Cooperation}

A number of policy and practical programmes exist to influence bi-regional research cooperation in FNSSA. Yet, more can be done to link research outputs to implementing or "spending" organisations, including government agencies, in order to ensure that research outputs lead to clear outcomes (CAAST-Net Plus 2016). There is a case for arguing that openness to fair international cooperation should be standardised within research teams, while intellectual property agreements (where relevant) and the funding of research exchanges should become the responsibility of research organisations. Standardising, and/or clarifying, visa regulations is one example of how international research exchanges can be facilitated. While clear and coherent public policies regarding research as well as IP regulation should be further implemented at the national level and the harmonisation of national rules and regulations and the organisation of multi-stakeholder forums should be instituted at the supra-national level. These factors should be addressed by all sides involved in the cooperative relationship.

Large-scale challenges remain, however. The fact that Europe has dominated the creation of funding mechanisms, and has greater access to resources as well as to human and infrastructural research capacity, is generally reflected in the division of roles within specific Africa-Europe research collaborations. In order to redress this imbalance and to achieve greater impact on the global FNSSA challenge-as duly recognised by the African governing institutions such as the AUC and NEPAD, together with African research coordinating platforms on agriculture (e.g. FARA)capacity development in STI in Africa has to be improved. Possible solutions could, for instance, include the implementation of more joint Africa-Europe doctoral programmes such as the ARPPIS-DAAD Ph.D. scholarships scheme in Kenya, or building upon expert consultations in thematic domains to support multi-disciplinary knowledge sharing, joint priority setting, planning and implementation as exemplified by the 
FNSSA partnership. Insofar as this endeavour can and should be addressed within the framework of the Africa-Europe R\&I cooperation, efforts should focus more on institutionalising collaborative funding programmes rather than using the unequal and politically biased provisions of development aid.

Outcome Testimonial: Long-lasting partnership through Partnership Platforms (dP-Cirad), Joint International Laboratories (LMI-IRD) or Joint International Research Units (UMI-CNRS): The example of RP-PCP in Zimbabwe. Compiled by Alexandre Caron (CIRAD) and Priscilla Mugabe (University of Zimbabwe) coordinators of the Partnership Platform.

In line with the agricultural policy of Zimbabwe, the research platform "Production and Conservation in Partnership" (RP-PCP) aims at contributing to sustainable development, nature conservation and improved rural livelihoods through strengthening national research capacities, multidisciplinary approaches and institutional partnerships. It focuses on protected and neighbouring production areas, with the aim to improve the coexistence of agricultural production and the conservation of natural resources for the benefit of rural communities.

Formally established in 2007, it was renewed in 2010 and 2015 until 2020 following external evaluations. The platform mobilises about 50-to-60 scientists from the Centre de Coopération Internationale en Recherche Agronomique pour le Développement (CIRAD), the National University of Science and Technology, the University of Zimbabwe and the Centre National de la Recherche Scientifique (CNRS). In 2014, it served as the driver of a project called DREAM, which was designed to strengthen and facilitate the links between research and development and its beneficiaries. Given the recognition it received and its high level of achievement, the platform has now entered a phase of institutional and regional expansion.

Under the Africa-Europe FNSSA partnership on R\&I, leading researchers in bi-regional collaborations have agreed on the need to sustain their work and ensure observable outcomes are achieved beyond the lifetime of individual projects. However, achieving this is easier said than done. Generally speaking, a number of prerequisites are required, including adherence to the principles of equal representation and collaboration, an in-built element of capacity building, and co-ownership through cofinancing and inclusive co-governance. Furthermore, communications and decision making should be transparent. 
For most FNSSA projects, participatory approaches involving all stakeholders are essential throughout the project cycle. A participatory approach can also serve as an entry point to better connect the research teams, private sector actors (including farmers' organisations, SMEs, and intermediaries) and decision-makers. In this regard, the projects funded under the ERAfrica framework could serve as a practical template for similar initiatives. Finally, Africa-Europe research platforms dedicated to agricultural research for development (AR4D) and FNSSA should be systematically mapped, their outputs evaluated and their practitioners linked with each other to form a strong community of practice.

\section{Outcome Testimonial: Partnerships to improve irrigation management in} small scale agriculture. Compiled by Jochen Froebrich (Wageningen University, Coordinator of the EAU4FOOD project).

Increasing agricultural productivity in Africa has long been a pressing issue and a key means to improve the livelihoods of people living in rural areas. Beginning in July 2011, we embarked on a mission to improve irrigation management in small-scale agriculture in Africa through the EU-sponsored project EAU4FOOD, involving several EU-based organisations working in partnership with selected African countries. With a total budget of 4.9 million euros our main objective was to improve agricultural productivity through innovations in irrigation. A key element of the project was the direct involvement of local stakeholders in the design, testing and dissemination of new and more effective soiland water management strategies. The so-called "Green Wheel Approach" was designed to involve stakeholders ranging from farmers, water managers and retailers to policymakers and non-governmental organisations alike.

Study sites were located in Mozambique, South Africa, Tunisia, Mali and Ethiopia in order to cover every region of the African continent and to obtain a baseline of usable data. In South Africa for instance, two cooperative farms were engaged to collaborate on increasing the yields for tomatoes by acquiring a better understanding of water scarcity in the region and by establishing better links to markets. Another example is the case study of Ethiopia where innovations were tested that aimed at tackling crop pests and improving soil fertility. The results observed in this study led to interest from the government of Ethiopia to further support maintenance of the irrigation infrastructure. Projects in the remaining study sites achieved similar results in terms of improving irrigation and soil fertility and eventually securing higher yields, and thus greater incomes for farmers.

Through this project we have gained direct experience of how inclusion can make a difference. We developed innovations in partnership with local farming communities and involved them in a process to come up with new practices and new ideas for agricultural practices. The EAU4FOOD project inspired new 
ways of managing irrigation and soil fertility and thus led to an increase in agricultural productivity and minimised the level of pollution of fresh water reserves. Additionally, the project led to changes in agricultural policy processes at national and trans-national levels. As such, it provided an observable contribution to furthering sustainable rural development in Africa by improving the understanding of the importance of irrigation for smallholder farmers.

\section{The Need for Alignment}

FNSSA is a complex, multi-dimensional, multi-sectoral issue with links to health, sustainable economic development, environment and trade. STI cooperation can operate in multiple dimensions and via numerous impact pathways. The policy priorities for Sub-Saharan Africa, as stated in the CAADP-FAFS, are to improve the physical and economic access to food and improve utilisation, especially to ensure a diverse diet and increase protein and micro-nutrient supply. Yet, the major focus of research cooperation projects tends to be developing data/knowledge bases, knowledge and information sharing platforms $(26 \%)$, with only $18 \%$ dedicated to food availability and $13 \%$ to utilisation. This suggests that current research cooperation projects might be too experimental and not concerned enough with "bread and butter" issues.

The paucity of data on soils and water scarcity, and the need for improving yields, as reported by several leading organisations including the FAO, suggest that future research collaborations for tackling the global FNSSA challenge might do well to target this basic ecological dimension of FNSSA (currently the case for only 12\% of projects) (CAAST-Net Plus 2014). Further applied research is needed into the mechanisation aspects (including irrigation) of FNSSA, in particular the role of small and medium-scale energy-efficient equipment and machinery. Since only a small percentage of projects currently appear to focus directly on food access, more attention is also needed on infrastructural development such as farm-market linkages as well as storage and warehousing systems. In addition, along with issues such as risk assessment for minimising the introduction of pathogens into predominantly European food markets, intellectual property rights and bio-based extracts for cosmetics, food safety is important for Sub-Saharan Africa and needs further attention under the FNSSA partnership.

Outcome Testimonial: Innovative organic fertilisers to improve food security. Compiled by Erick Rajaonary (Chief Executive Officer: GUANOMAD, Madagascar). 
Producing more and better food is vital for securing better lives for millions of people around the world, especially in Sub-Saharan Africa where one in four people remain undernourished. Part of the solution to address this challenge lies in bridging the gap between the private and the public sector. The recurring Africa-Techno Conference, organised by the French organisation CVT, exists to present technologies developed in Africa or Europe that address, among other issues, food security and agri-food. The aim of this event is to identify potential partners or investors in order to scale up the use of innovative solutions to tackle a range of societal challenges. One such technology led to the creation of GUANOMAD in 2006, a Malagasy SME that was supported by the EU-funded African Agriculture SME Fund.

GUANOMAD is a producer of fertiliser drawn from bat excrement. The fertiliser can be used for various crops and is suitable for a broad range of customers. On average $500 \mathrm{~kg}$ of GUANOMAD is needed to cultivate one bectare of rice in the first year, while only $425 \mathrm{~kg}$ and $380 \mathrm{~kg}$ of GUANOMAD fertiliser is needed for the second and third year respectively. Thus, fertiliser use is decreased while harvest yields remain stable and the quality of products improves. This enables the production of organic vegetables, fruits and other horticultural products that in turn help improve food-and nutrition security. GUANOMAD is certified by Ecocert (an organic certification organisation) and thus reduces the use of chemical fertilisers, which benefits the environment.

As part of its funding GUANOMAD also benefitted from technical assistance facilities that included 60.000 euros for export strategy \& distribution as well as 250.000 euros for agri-dealer training. As a result, the SME has established contact with agri-dealers in Africa, Europe and the US and are exporting the fertiliser to more than 30 countries. Through the agri-dealer training programme, 100 distributors in the GUANOMAD network benefitted from training to provide technical assistance to local communities and farmers' organisations on how to use the organic fertiliser. The support helped to strengthen the distribution network of GUANOMAD and enabled a scaling up of its operations.

Due to its success of contributing to food security, GUANOMAD has been showcasing its business model at various international conferences. Its involvement in CAAST-Net Plus was a vital stepping-stone towards achieving this by offering a platform for identifying partners and exchanging best practices.

In terms of geographic participation, the main food insecure countries are located in West, Eastern and Central Africa, whereas the majority of the Sub-Saharan African project participants are located in South and East Africa. Western and Central African countries such as the Central African Republic, Chad, the Democratic Republic of Congo and Niger are seldom 
represented, perhaps reflecting poor STI capacities and networks between these countries and European counterparts. However, some French research agencies (e.g. IRD and CIRAD) are very active in West and Central francophone Africa, while other EU member states have bilateral projects that also target countries in these sub-regions. This provides a starting point from which to build broader collaborative efforts though, as part of this, consideration should be given to utilising funding mechanisms that minimise a "winner takes all" scenario. This will encourage the pursuit of high-quality scientific endeavours based also on insights and capacities from "outliers" within Africa as well as (at both organisational and country levels) to address the global FNSSA challenge.

On the European side, there tends to be low engagement from Eastern European countries even though they face their own related challenges such as food safety and quality, EU market access/penetration, poor infrastructure, and poor policy instruments. As such, these countries could surely benefit from collaborating with African counterparts dealing with similar challenges. Yet, countries such as Bulgaria, Latvia and Poland are poorly represented in Africa-Europe projects, as opposed to Western European countries such as France, Germany, the Netherlands and the United Kingdom. On the African side conflict-prone areas such as Sudan and the Democratic Republic of Congo are hardly covered either; while there are historical causes for this, which can hardly be reversed overnight, this should not discourage ever-increasing efforts to foster the participation of other EU member states, to bring fresh ideas to the fore and to address shared challenges together.

This chapter has thus far focused primarily on the benefits of biregional STI collaboration for African FNSSA, saying relatively little about the reciprocal benefits for Europe. To a large extent, this reflects the fact that the relationship between the two continents has a baggage of longstanding inequality, itself the product of vastly different paces in development, notably as regards STI capacity and infrastructure. For many years, European engagement with Africa was primarily in the form of development aid, which, while very useful for the continent's advancement, has created asymmetries. While there is a real desire and drive to establish greater equality in the Europe-Africa partnership (as testified by projects such as ERAfrica), the legacy of historical imbalance slows the pace of transformation. This is particularly true since the capacity building and infrastructure development, required to achieve full equality of means, are 
still reliant on a greater contribution from the European side even in collaborations based on equal partnership. At the same time, African states could play a "mentoring" role in STI development, which would translate into greater global influence, by pursuing partnerships not only with the larger, historically more familiar European partners but with smaller, less developed European countries (notably in Eastern Europe as noted above) as well as on a regional level.

Having largely addressed the problem of food production in terms of sufficient quantity, Europe is now steadily pivoting towards efforts to increase the nutritional benefits of its yields while also retaining biodiversity, adapting to climate change and reducing greenhouse gas emissions. This effort is exemplified by the Joint Programming Initiative on Agriculture, Food Security and Climate Change (FACCE-JPI), which unites $22 \mathrm{EU}$ countries in addressing "the interconnected challenges of sustainable agriculture, food security and impacts of climate change" (www.faccejpi.com, 2017). Here Africa has many insights to offer. While the primary concern is still overcoming recurrent food shortages, a number of existing research initiatives focus specifically on improving the nutritional quality of food such as Folate Intake in European and African Countries, an ERAfrica-funded project that seeks combat vitamin deficiency by increasing the folate contents of traditional cereal staple foods through fermentation. Or in developing agricultural practices aimed at maintaining biodiversity, exemplified by a collaboration between CIRAD and the University of Pretoria around the cultivation of rooibos.

Research projects designed around the concept of equal partnership as applied not only to input but also benefit would ensure a two-way flow of information and value-addition alike, allowing both Africa and Europe to gain from the collaboration in equal measure. Fortunately, there is a real awareness of this fact: thanks to the Africa-Europe dialogue, it has become clear that the European model for agriculture is being questioned and African policy makers are pursuing models more appropriate to their contexts. Policymakers of both continents are conscious of the fact that we live on a single, interconnected, planet, and that we face the same challenges presented by climate change and the reality of finite natural resources. African and European policy makers have also realised that solutions must be localised and take into account local constraints and specificities. For example, the French Ministry of Agriculture is currently promoting agri-ecology in France based on concepts which were 
initially developed in Africa, while Europe in turn has launched a programme named LEAP-AGRI (http://www.leap-agri.com, 2017) to support Africa-EU partnerships on priority topics of the FNSSA roadmap (European Commission 2016).

\section{Conclusion}

A wider and more intense cooperation is needed in order to strengthen African and European STI policies and practices for greater FNSSA. Such cooperation should strive to draw partners closer together: to harmonise their skills, capacities and resources, while systematically ensuring the equal representation in and ownership of collaborative ventures. Everything else should follow naturally.

Outcome Testimonial: The HLPD and the LEAP-AGRI Project. Compiled by Johan Viljoen (IRD, Project Manager for CAAST-Net Plus).

In shared recognition of the importance of STI for societal-and economic growth, the HLPD emerged as the governing body of the JAES STI partnership. Understanding the vital role played by FNSSA as part of the process of development and growth, and in the face of increasing food scarcity and global hunger, the HLPD catalysed the creation of an Africa-Europe Research and Innovation Partnership in FNSSA aimed at proposing both short and long-term actions in order to address shared challenges in this regard. This partnership, in its conception, was to be co-owned and co-funded, as well as aligned with all the major policy developments in both Africa and Europe in the field of FNSSA. The FNSSA partnership is guided by the so-called "FNSSA roadmap", a strategy based on four priority themes meant to serve as basis for a joint Africa-Europe research plan: sustainable intensification, agriculture and food systems for nutrition, expansion and improvement of agricultural trade and markets, and a number of cross-cutting topics.

Within this framework, the LEAP-AGRI project was initiated as flagship collaboration with the objective of increasing joint Africa-Europe investment in FNSSA so as to reduce fragmentation in the field, involving 22 European and African countries and a total budget of more than 22 million euros. In addition to the proposed funding of new joint research projects, LEAP-AGRI seeks to identify and develop existing instruments for cooperation between the two continents, more particularly to involve the participation of the private sector, development organisations and civil society. Guided by the governance principles of partnership, equal participation and long-term commitment, LEAP-AGRI operates within the funding framework of the EU Horizon 2020 programme, and expects among many other results to produce a comprehensive joint Strategic Research and Innovation Agenda for EU-Africa FNSSA. 


\section{REFERENCES}

CAAST-Net Plus. (2014). Africa-EU research collaboration on food security: A critical analysis of the scope, coordination and uptake of findings. Available from: https:/ caast-net-plus.org/object/news/1212/attach/CN__FoodSecurityReport_ v7.pdf. Accessed 16 May 2017.

CAAST-Net Plus. (2016). Framework conditions for bi-regional cooperation in the field of food and nutrition security. Available from: https://caast-net-plus.org/ object/document/1626/attach/D1_4_FINAL_WEB.pdf. Accessed 9 May 2017.

European Commission. (2009). A strategic European framework for international science and technology cooperation. Available from: http://ec.europa.eu/ research/press/2008/pdf/com_2008_588_en.pdf. Accessed 9 May 2017.

European Commission. (2016). Roadmap towards a jointly funded EU-Africa research innovation partnership on food and nutrition security and sustainable agriculture. Available from: https://ec.europa.eu/research/iscp/pdf/policy/ eu-africa_roadmap_2016.pdf. Accessed 9 May 2017.

Forum for Agricultural Research in Africa. (2013). Science agenda for agriculture in Africa (S3A): A report of an expert panel. Accra: FARA.

NEPAD. (2014). On the wings of innovation: Science, technology and innovation for Africa 2024 strategy (STISA-2024). Available from: http://www.hsrc.ac.za/ en/events/seminars/science-tech-and-innovation-strategy. Accessed 16 May 2017.

Open Access This chapter is licensed under the terms of the Creative Commons Attribution 4.0 International License (http://creativecommons.org/licenses/ by $/ 4.0 /$ ), which permits use, sharing, adaptation, distribution and reproduction in any medium or format, as long as you give appropriate credit to the original author(s) and the source, provide a link to the Creative Commons license and indicate if changes were made.

The images or other third party material in this chapter are included in the chapter's Creative Commons license, unless indicated otherwise in a credit line to the material. If material is not included in the chapter's Creative Commons license and your intended use is not permitted by statutory regulation or exceeds the permitted use, you will need to obtain permission directly from the copyright holder.

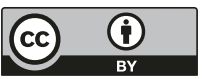

